\title{
Capillary surface area is reduced and tissue thickness from capillaries to myocytes is increased in the left ventricle of streptozotocin-diabetic rats
}

\author{
A. Warley ${ }^{1}$, J.M.Powell ${ }^{2}$, J.N.Skepper ${ }^{2}$ \\ ${ }^{1}$ Department of Physiology, United Medical and Dental Schools, St. Thomas' Hospital, London, UK \\ ${ }^{2}$ The Multi-Imaging Centre, Department of Anatomy, University of Cambridge, Cambridge, UK
}

Summary The left ventricles of normal and diabetic rats, fixed by vascular perfusion were examined using modern stereological techniques to quantify changes in the morphology accompanying streptozotocin-induced diabetes. The heart weight to body weight ratio increased in diabetic rats whilst left ventricular volume remained unchanged. Papillary muscles from the diabetic animals showed prolonged time to peak tension and relaxation, and altered sensitivity to adrenalin and calcium. The apparent cardiomyopathy observed when body weight loss exceeds heart weight loss in experimental diabetes was accompanied by specific pathological changes in the composition of the left ventricle. In the diabetic animals the volume of extracellular components increased threefold and the volume of capillaries fell. The surface density and total surface area of capillaries was reduced, and oxygen diffusion distance to myocyte mitochondria increased. The volume fraction of myocyte mitochondria was reduced during streptozotocin-induced diabetes. [Diabetologia (1995) 38: 413-421]

Key words Capillaries, cardiomyopathy, diabetes, diffusion, streptozotocin, myocardium, myocytes, oxygen, stereology.
Cardiovascular disease is a serious complication of diabetes mellitus, death from disease of the cardiovascular system being some two-to three-fold higher than in the general population. A number of these deaths are due to ischaemia caused by atherosclerosis, but there is also evidence that the myocardium itself is directly affected and that a cardiomyopathy develops [1-3].

Animal models are frequently used for the study of diabetes and cardiac function is known to be depressed in rats with drug-induced diabetes [4]. Studies on isolated papillary muscle have also shown alteration in function in the diabetic rat heart; decreases in developed tension, reduced shortening velocity,

Received: 13 July 1994 and in revised form: 11 October 1994

Corresponding author: Dr. J.N. Skepper, The Multi-Imaging Centre, University of Cambridge, Downing Street, Cambridge CB2 3DY, UK

Abbreviations: XSA, cross-sectional area. slowed relaxation time, and prolonged time to peak tension have all been reported [5-8].

A number of investigations have been carried out to determine structural alterations which might underlie the altered function in drug-induced diabetes, but the results from these studies are varied. Most have concentrated mainly on the ultrastructure of the cardiac myocyte. Varying degrees of damage have been reported, from no damage at all to loss of myofibrils, intracellular oedema, and/or distortion of mitochondria [9-13]. Thickening of the capillary basal lamina has also been reported by a number of authors $[11,12,14]$. Studies on tissue from diabetic humans have been equally inconclusive. Reported changes have included increased thickness of ventricular arterial walls in diabetic patients with no apparent changes in the relative densities of their capillaries and no significant changes in intramyocardial arteries $[15,16]$.

In the studies on diabetes in rats, some of the described variations could be related to the wide range of experimental procedures adopted; for example, 
the use of different agents to induce diabetes, varying doses of drugs, inconsistent duration of diabetes, and animals of incompatible age or weight. The methods used for tissue preparation might also have some influence. The use of immersion rather than perfusion fixation, might account for some of the observed cellular damage. In addition, many of the results are subjective, and the exact extent of any changes is not clear. The majority of studies were carried out before modern stereological techniques became more widely used. This paper reports the results of a stereological study to determine changes in structure in cardiac tissue from streptozotocin-diabetic rats.

\section{Materials and methods}

General preparation. Two groups of sexually mature (10-weekold) male Carworth Sprague Europe (CSE) Wistar rats were used in this study. Two groups of eight rats were chosen by lottery; both had mean body weights of approximately $300 \mathrm{~g}$. In one group diabetes was induced by a single intraperitoneal injection of streptozotocin $(55 \mathrm{mg} / \mathrm{kg}$ body weight); the second group were used as untreated onset controls and were fixed immediately for light and electron microscopy as described below. The diabetic animals were allowed free access to food and water, and maintained for a period of 40-50 days. After this time the animals were weighed and heart tissue was fixed for light and electron microscopy. Treatment of the animals conformed with the Home Office Guidance on the operation of the animals (Scientific Procedures) Act 1986, published by Her Majesty's Stationery Office, London.

The rats were deeply anaesthetized with sodium pentobarbitone, a midline laparotomy was performed and the abdominal aorta was cannulated. A 1-ml sample of blood was withdrawn for glucose analysis and a 1-ml bolus of heparin was injected. An incision was made in the adjacent vena cava and the animals were exsanguinated by perfusion with physiological saline containing a final concentration of (in $\mathrm{mmol} / \mathrm{l}$ ): 10 PIPES buffer, 139 sodium chloride, 2.7 potassium chloride, 19.4 glucose, 0.0075 polyvinylpyrrolidone with a molecular weight of 40000 (PVP-40) and $1 \%$ procaine at a $\mathrm{pH}$ of 7.2 . This perfusion was continued until the heart ceased beating, typically 1-2 min. The combination of perfusion with a calcium-free saline and the addition of a vasodilator, ensured that the hearts were fixed in diastole with maximum vascular dilation. Exsanguination was followed by perfusion with $500 \mathrm{ml}$ of a fixative containing $3 \%$ glutaraldehyde, $0.5 \%$ formaldehyde and $2.5 \%$ PVP-40 in $0.1 \mathrm{~mol} / 1$ PIPES buffer at $\mathrm{pH}$ 7.2. Both solutions were maintained at a temperature of $20^{\circ} \mathrm{C}$. The perfusions were maintained at a pressure of $90 \mathrm{~mm} \mathrm{Hg}$; monitored manometrically, this value corresponds to the blood pressure of these animals, as determined experimentally. The PVP-40 was added as a high molecular weight colloid to minimise oedema [17]. The fixed organs were removed and the right and left ventricles were dissected free, blotted and weighed individually. Heart weight to body weight ratios were calculated for both groups of rats using the body weight of the anaesthetized rat and the wet weight of the fixed heart. Blood glucose levels were measured using a blood glucose analyser [18].

The volume of the left ventricle (including the interventricular septum) was estimated by weighing it suspended, then immersing it in saline and multiplying the weight of saline dis- placed by its specific gravity [19]. The left ventricle was sectioned coronally into six equal slices. Either the first or second slice was chosen by lottery, and every subsequent second slice was taken until a total of three slices had been selected. Two pieces of each slice chosen were processed further, after isotropic uniform random planes of section were identified using the orientator principle [20]. A total of six samples per animal was therefore achieved. Tissues were rinsed in $0.1 \mathrm{~mol} / \mathrm{l}$ PIPES buffer, osmicated, bulk stained, dehydrated in an ascending series of ethanol solutions and embedded in Taab embedding resin. Sections were cut at a nominal thickness of $1 \mu \mathrm{m}$ using a Reichert Ultracut E (Vienna, Austria), stained with methylene blue and viewed using a Leitz Laborlux S (Wetzlar, Hessen, Germany). The same block faces were sectioned for transmission electron microscopy and sections were mounted on 300-mesh grids and stained with uranyl acetate and lead citrate.

Stereology. An estimate of volume changes in the tissue was made by measuring the diameter of equatorially-sectioned erythrocytes from control rats and comparing their mean diameter with that of known physiological values. This revealed an overall shrinkage of less than $4 \%$ which was considered to be negligible and was subsequently ignored. Subsequent morphometric analysis was carried out at two levels.

At level $1(\times 1000)$ the volume fractions of the left ventricle occupied by myocytes and all other components of the intermyocyte space was estimated from the $1-\mu \mathrm{m}$ sections. Ten fields from each section were identified using a systematic random sampling routine starting from a random location outside each section. Each field was overlain with a 121-point square lattice and the tissue was divided into myocytes, capillaries, other blood vessels and extracellular space. The estimates of volume fractions of cardiac components were converted into volumetric data $\left(\mathrm{mm}^{3}\right)$ by multiplying the volume of the left ventricle by the volume fraction of each component. Estimates of length and surface density of capillaries (including post-capillary venules) were made at the same magnification using a Merz curvilinear test system with 36 points, a 19.3- $\mu \mathrm{m}$ spacing and a field area of $0.0134 \mathrm{~mm}^{2}$. The Merz test system was chosen to increase the efficiency of sampling of an anisotropic tissue. Nine fields were selected per section in a systematic random fashion starting from a point off the section, giving a total of 54 fields per animal. The numerical density $\left(Q_{A}\right)$ of capillary profiles was counted using the same frame and observing the forbidden line rule [21]. The length density of capillaries $\left(\mathrm{mm} / \mathrm{mm}^{3}\right)$ was then estimated from $L_{V}=2 \cdot Q_{A}$ [19]. The total length of capillaries and post-capillary venules per left ventricle was estimated by multiplying the length density by the volume of the left ventricle.

The surface density of capillaries $\left(\mathrm{mm}^{2} / \mathrm{mm}^{3}\right)$ was estimated from $S_{V}=2 . I_{L}$ [19]. The total surface area of capillaries and post-capillary venules was estimated by multiplying this value by the volume of the left ventricle. The mean diameter (D) of capillaries (including post-capillary venules) was obtained by estimating their cross-sectional area (XSA) from $\mathrm{V}_{\mathrm{v} \text { capillaties }}$ $\mathrm{L}_{\mathrm{v} \text { capillaries }}$ and then multiplying the square root of $\mathrm{XSA} / \pi$ by 2 [22]. To obtain a direct estimate of capillary diameter, near circular capillary profiles, having an axial ratio of better than 1.1:1 and a diameter of less than $8 \mu \mathrm{m}$ (following the criteria of Hyde and Buss [23]), was measured from the projected 35$\mathrm{mm}$ films used in level 2. A minimum of 100 profile diameters were measured from each animal.

At level $2(\times 16500)$ the arithmetic and harmonic mean of tissue thicknesses from capillary lumen to myocytes and underlying mitochondria $\left(T_{a}\right.$ and $\left.T_{h}\right)$ and the volume fraction $\left(V_{v}\right)$ of myocytes occupied by various organelles were estimated from $35-\mathrm{mm}$ electron micrograph negatives projected onto the 
Table 1. General characteristics of control $(n=8)$ and diabetic $(n=8)$ Wistar rat hearts

\begin{tabular}{lllll}
\hline $\begin{array}{l}\text { Duration of diabetes } \\
\text { (days) }\end{array}$ & $\begin{array}{l}\text { Blood glucose } \\
(\mathrm{mmol} / \mathrm{l})\end{array}$ & \begin{tabular}{l} 
Body weight \\
\cline { 3 - 4 }
\end{tabular} & start $(\mathrm{g})$ & \multicolumn{2}{c}{$\begin{array}{l}\text { Heart weight/body weight ratio } \\
(\%)\end{array}$} \\
\hline Control 0.0 & $4.2 \pm 0.2$ & $302 \pm 6$ & end $(\mathrm{g})$ & $0.26 \pm 5$ \\
Diabetic $48 \pm 1.1$ & $19.6 \pm 3.1^{\mathrm{a}}$ & $304 \pm 24 \mathrm{NS}$ & $235 \pm 12$ & $0.35 \pm 1^{\mathrm{a}}$ \\
\hline
\end{tabular}

Values are means \pm SEM. Comparison between control and diabetic groups was made using the Student's $t$-test; NS, no significant difference; ${ }^{\mathrm{a}} p<0.005$

digitising tablet of a Kontron videoplan. Thin sections were sampled in a systematic random manner to obtain ten negatives per section. To estimate tissue thicknesses the images were projected onto a series of parallel, vertical lines $3 \mu \mathrm{m}$ apart. Orthogonal intercept lengths were measured in two situations: 1. whenever a test line intersected a mitochondrial outer membrane the intercept length to the nearest capillary luminal membrane was measured. This was considered to be related to the global mean diffusion distance for oxygen from the capillary lumen to the mitochondria of the cardiac myocytes. 2 . Whenever a test line intersected a capillary luminal membrane the intercept length to the nearest myocyte sarcolemma was measured. This was considered to be the tissue thickness between the capillary lumen and the sarcolemma of the surrounding cardiac myocytes. In both cases all 60 negatives were used; this was sufficient to generate a minimum of 200 intercepts per rat. The orthogonal intercepts were converted to $T_{a}$ and $T_{h}$ by multiplying the arithmetic and harmonic means of the orthogonal intercept lengths by $\pi / 4(0.7854)$ or $8 / 3 \pi(0.8488)$, respectively [24]. A uniformity index of tissue thickness was obtained from $\mathrm{T}_{\mathrm{a}} / \mathrm{T}_{\mathrm{h}}$ [25]. This gives an indication of the regularity of the diffusion distance with unity representing a tissue of even thickness.

To estimate the volume fraction of the various organelles in myocytes a double square lattice with spacings of $0.5 \mu \mathrm{m}$ and $5 \mu \mathrm{m}$ was used. The larger spacing was used for estimates of the volume fractions of myofibrillae, mitochondria and cytoplasm. The smaller lattice was used for estimates of the volume fractions of lipofuscin, lipid droplets and elements of the T-system. Every other negative used in the estimates of barrier thickness was counted giving a sample of 30 micrographs per rat. These negative were projected to a final magnification of $\times 50000$ and square lattice with a $5 \mu \mathrm{m}$ spacing was used to estimate the volume fraction of components of the intermyocyte space. These were classed as collagen fibrils, amorphous ground substance and other components, including fibroblasts, neural elements etc.

Functional studies. Experiments to demonstrate that function was altered in the diabetic hearts were carried out on a small number of animals ( $n=6$ for controls and $n=4$ for diabetic rats). Diabetes was induced according to the protocol outlined above. At the end of the experimental period, rats were anaesthetized and the hearts quickly removed. A left ventricular papillary muscle was excised and mounted in a superfusion chamber. The muscle was secured at one end to a fixed stainless steel hook and at the other end to an isometric tension transducer using a fine silk suture. The preparations were superfused with a modified Ringer's solution at a flow rate of $10 \mathrm{ml} / \mathrm{min}$. The muscle was constantly field stimulated via flat platinum electrodes on either side of the channel at a rate of $1 \mathrm{~Hz}$ and a pulse width of approximately $2 \mathrm{~ms}$. The preparations were equilibrated for $90 \mathrm{~min}$. At the end of this period the superfusate was replaced by buffer containing the appropriate concentrations of either calcium or adrenaline. Superfusion was continued until the response of the preparation was stable. The muscle was then superfused with the standard buffer until the response returned to normal. These methods have been described in detail in an earlier study [26].

\section{Statistical analysis}

Values quoted are means \pm SEM. Statistical analysis was carried out using the Statgraphics statistical package. Comparison was made between the two groups using an unpaired two-tailed Student's $t$-test with $p<0.05$ being considered as statistically significant.

\section{Results}

General characteristics and functional studies. The rats which had been injected with streptozotocin showed symptoms of diabetes in that they lost weight, and blood glucose levels were increased fourfold in comparison with the controls (Table 1). As a result of body weight loss, the heart-weight to bodyweight ratio was increased by approximately $25 \%$ in the diabetic rats. Data from control and diabetic animals are given in Table 1.

Under our experimental conditions both time to peak tension ( $62 \pm 6 \mathrm{~ms}$, controls, $n=6,123 \pm 20 \mathrm{~ms}$, diabetic rats, $n=4)$ and time to $75 \%$ relaxation ( $66 \pm 3 \mathrm{~ms}$ controls, $121 \pm 33 \mathrm{~ms}$, diabetics) were significantly increased in the papillary muscles from the diabetic animals, $p<0.05$. The isolated muscles also showed a reduced sensitivity to increased concentrations of calcium (Fig.1 A) and adrenalin (Fig. 1B) in the bathing medium.

Stereological studies. Stereological analysis showed that in the left ventricle from the diabetic rats there was a decrease in the volume fraction of the left ventricle occupied by cardiac myocytes in comparison with control rats $(p<0.01)$. This was accompanied by an increase in the volume fraction of inter-myocyte space in the diabetic left ventricle $(p<0.01)$. When the components of the inter-myocyte space were examined individually there was no significant difference in the volume fraction of larger blood vessels (including arteries, veins and arterioles) between the diabetic and control group. However, there was a 

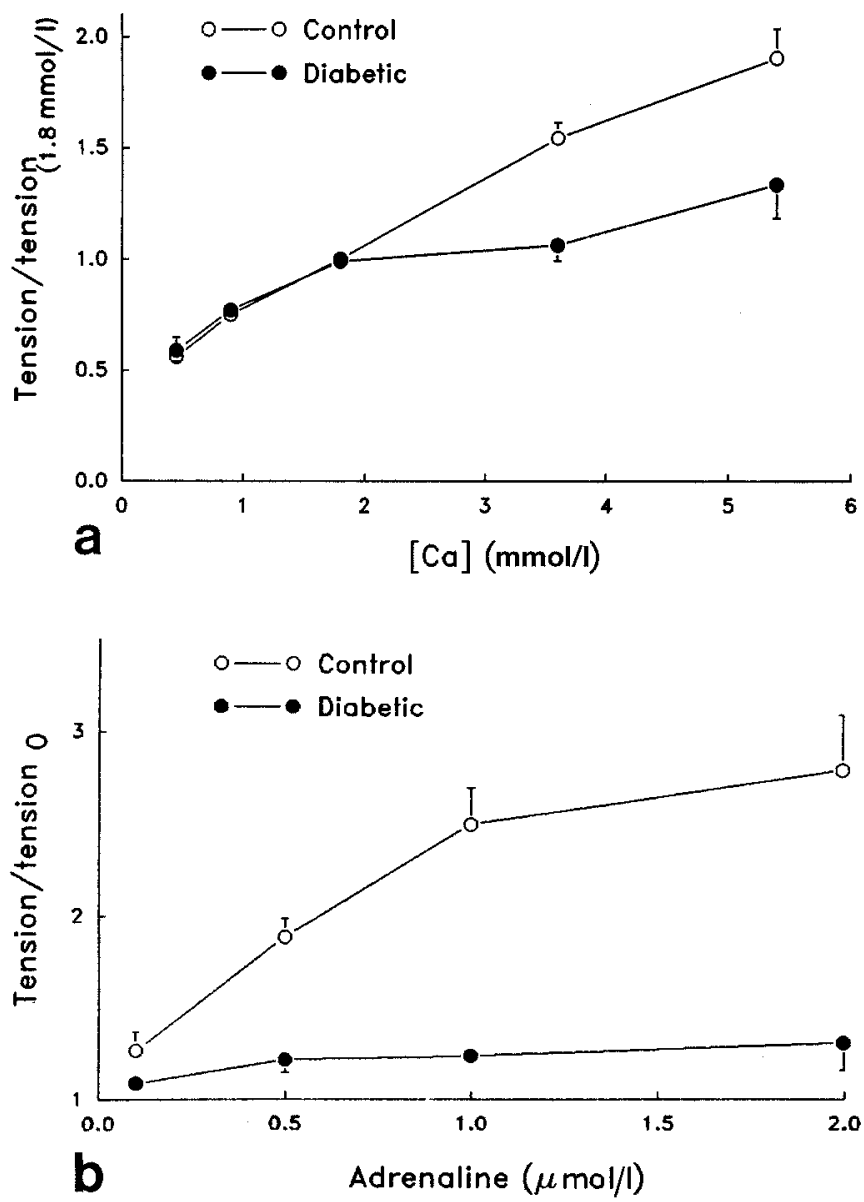

Fig.1a. Effect of calcium concentration on contractile function in left ventricular papillary muscles from normal and diabetic rats. Tension is expressed as a proportion of that at the control [Ca] of $1.8 \mathrm{mmol} / \mathrm{l}$. b. Effect of adrenalin on cardiac muscle function. Tension is expressed as a proportion of the control value without added adrenalin

significantly lower volume fraction of capillaries and post-capillary venules $(p<0.001)$ in the diabetic animals. The increase in inter-myocyte space was accommodated by an increase in the volume fraction of other components of the extracellular space $(p<0.001)$ including fibroblasts, neural elements and non-cellular components such as collagen and ground substances. The volume fractions of cellular and noncellular components are summarised in Table 2. Examination by low-power electron microscopy revealed an increase in the dimensions of the spaces between cardiac myocytes (Fig. $2 \mathrm{a}, \mathrm{b}$ ). In some regions this was accompanied by deposition of collagen fibrils (Fig.2c) but in others the inter-myocyte space was only occupied by amorphous components of the ground substances.

When these components were examined as volumetric data to see if there was any alteration in any of the reference spaces a slightly different pattern emerged. There was no significant difference in the total volume of the left ventricle between the control and the diabetic rats. There was no significant differ- ence in the volume of myocytes in the left ventricle between the two groups of animals. The volume of inter-myocyte space was $25 \%$ greater in the diabetic animals $(p<0.01)$. The volume of blood vessels (arteries, veins and arterioles but excluding capillaries and post-capillary venules) was not significantly different between the two groups. The volume of capillaries and post-capillary venules was significantly less in the diabetic rats $(p<0.01)$. These results show that the overall increase in the mass of intermyocyte space of the diabetic animals was accommodated by a massive increase in the volume of the other components of the extracellular space, which include connective tissues, ground substances and neural elements. These data are summarised in Table 2.

There was a significantly greater volume fraction of collagen fibrils $(p<0.05)$ and amorphous ground substance $(p<0.05)$ in the intermyocyte space of the diabetic animals but no significant difference in its other components. When these data were expressed in terms of their actual volumes there was a significantly greater volume $(p<0.001)$ of amorphous ground substance in the left ventricle of the diabetic animals. However, there was no significant difference in the volume of collagen fibrils or other components between the two groups. These data are summarised in Table 3.

There was no significant difference in either the length density or the total length of capillaries and post-capillary venules in the left ventricle between the diabetic animals and the control rats. However, there was a significantly lower surface density of capillary and post-capillary venule luminal surface in the diabetic rats when compared with the controls $(p<0.001)$. The total surface area of capillaries and post-capillary venules was also lower in the diabetic rats $(p<0.001)$, but there was no significant difference in the mean diameter of capillaries and post-capillary venules in the diabetic rats in comparison with control rats. However, when the mean diameter of near-circular profiles of capillaries having diameter of less than $8 \mu \mathrm{m}$ was compared, the mean diameter of capillaries in the diabetic myocardium was significantly less $(p<0.001)$ than those in the control myocardium. These data are summarised in Table 4.

Both the arithmetic and the harmonic mean of the tissue thicknesses from capillary lumen to myocyte sarcolemma were significantly greater in the diabetic myocardium ( $p<0.001$ and $p<0.005$, respectively). There was no significant difference in the uniformity index of this tissue thickness between the two groups. These data are summarised in Table 5.

There was no significant difference in arithmetic mean of the tissue thickness between myocyte mitochondrial outer membranes and capillary luminal membranes. The harmonic mean of tissue thickness however, was greater in the diabetic left ventricle $(p<0.01)$. The uniformity index of tissue thickness 
Table 2. Volume fractions (\%) and volumes $\left(\mathrm{mm}^{3}\right)$ of cellular and non-cellular components of the left ventricle of control $(n=8)$, and diabetic $(n=8)$ Wistar rat hearts

\begin{tabular}{lccllll}
\hline & $\begin{array}{l}\text { Extracellular } \\
\text { space }\end{array}$ & Capillaries & Blood vessels & $\begin{array}{l}\text { Total inter- } \\
\text { myocyte space }\end{array}$ & myocytes & Left ventricle \\
\hline $\begin{array}{l}\text { Volume fraction }(\%) \\
\text { Control }\end{array}$ & $6.37 \pm 0.8$ & $17.04 \pm 0.4$ & $6.50 \pm 0.4$ & $29.91 \pm 0.8$ & $70.09 \pm 0.8$ & \\
$\begin{array}{l}\text { Diabetic } \\
\text { Volume }\left(\mathrm{mm}^{3}\right)\end{array}$ & $18.99 \pm 2.0^{\mathrm{b}}$ & $12.63 \pm 0.8^{\mathrm{b}}$ & $5.39 \pm 0.6 \mathrm{NS}$ & $37.01 \pm 2.5^{\mathrm{a}}$ & $62.99 \pm 2.5^{\mathrm{a}}$ & \\
$\begin{array}{l}\text { Control } \\
\text { Diabetic }\end{array}$ & $40.70 \pm 5$ & $110.30 \pm 4$ & $42.40 \pm 3.0$ & $193.70 \pm 7.0$ & $453.70 \pm 16.0$ & $647.1 \pm 19$ \\
\hline
\end{tabular}

Values are means \pm SEM. Comparison between control and diabetic groups was made using the Student's $t$-test; NS, no significant difference; ${ }^{\mathrm{a}} p<0.01 ;{ }^{\mathrm{b}} p<0.001$
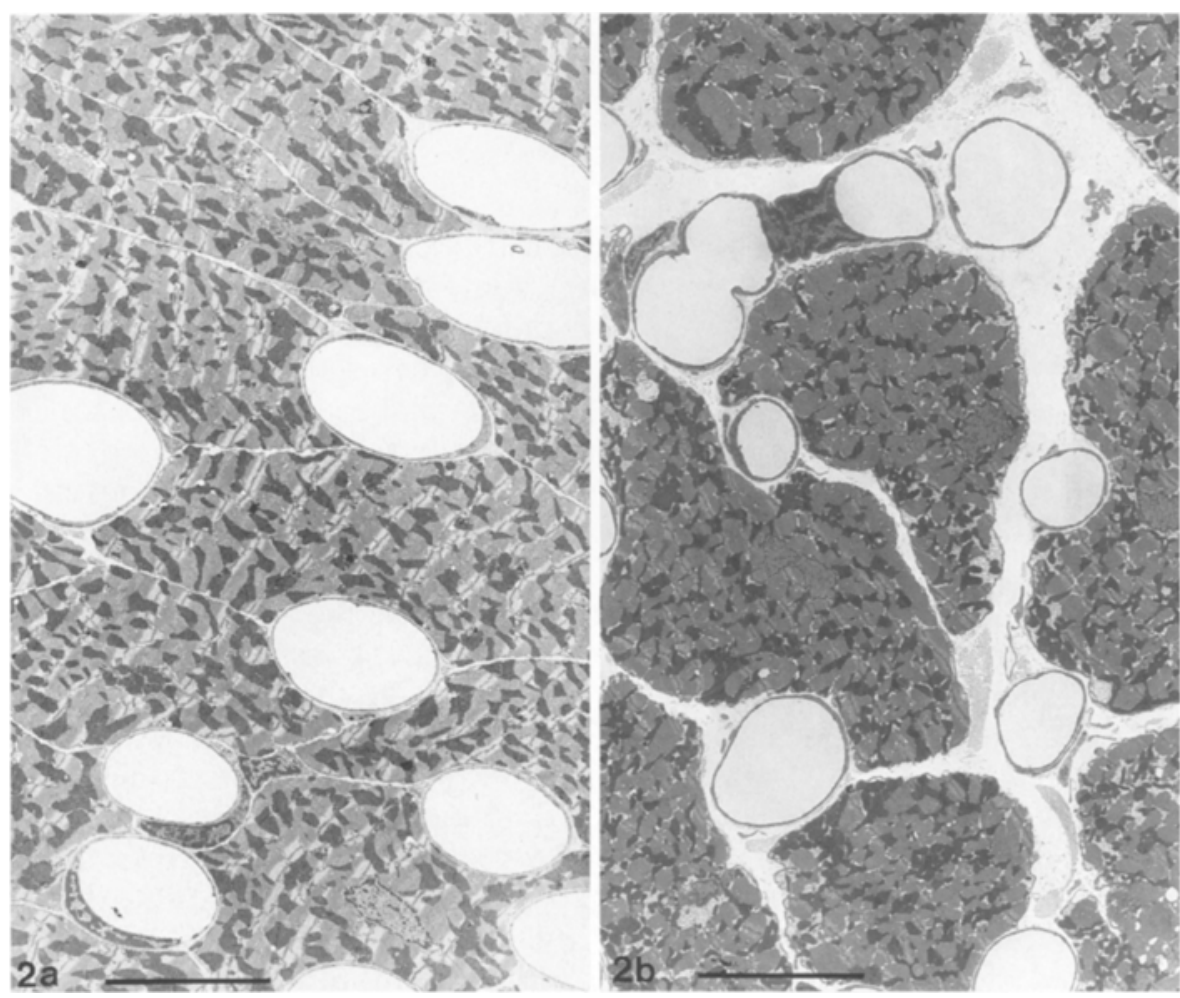

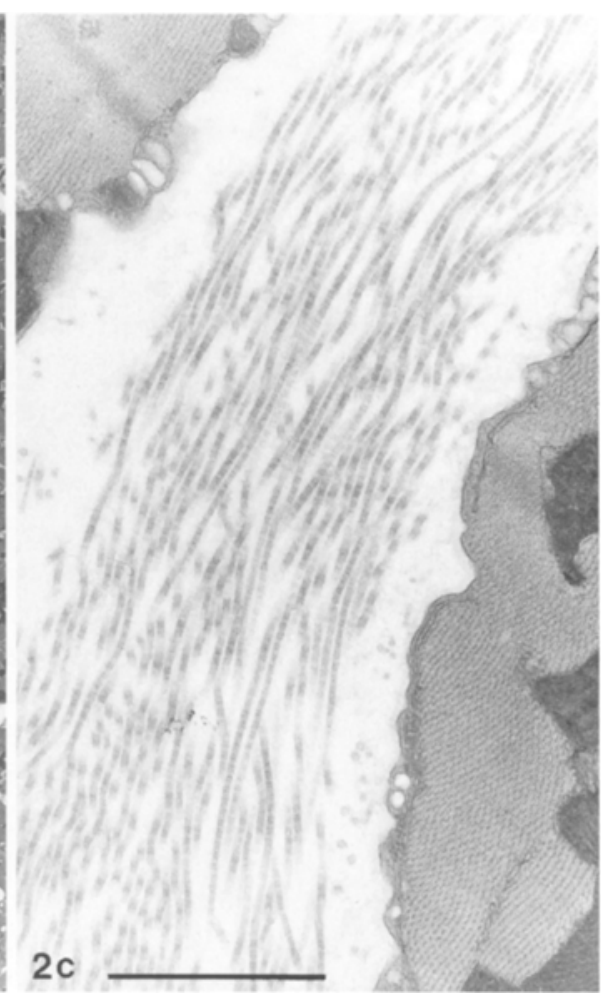

Fig. 2a. Low-power electron micrograph of the left ventricular wall of a control rat, cut at near transverse section demonstrating closely packed cardiac myocytes with little intermyocyte space. $\times 2350$, scale bar $10 \mu \mathrm{m}$ b. Electron micrograph of a similar region from a diabetic rat. The intermyocyte space is considerably enlarged. $\times 2400$, scale bar $10 \mu \mathrm{m}$ c. Electron micrograph of the enlarged intermyocytes space from a diabetic rat viewed at higher magnification. In this region there is increased deposition of collagen fibrils. $\times 30600$, scale bar $1 \mu \mathrm{m}$ significantly reduced $(p<0.001)$ at the end of the diabetic period. There was no significant change in the volume of either myofibrillae or lipofuscin, but the volume of all other components of the myocytes, designated simply cytoplasm, was significantly increased $(p<0.001)$ at the end of the diabetic period. These data are summarised in Table 6.

\section{Discussion}

was significantly less $(p<0.001)$ in the diabetic myocardium.

The volume fractions of the various organelles within the left ventricular cardiac myocytes was considerably different 48 days after the onset of diabetes. The volume of lipid droplets and of elements of the T-system was significantly increased (both $p<0.001$ ) whereas the volume of mitochondria was
Streptozotocin-induced diabetes is now a well-accepted model for the study of long-term complications of the disease. The dose of streptozotocin $(55 \mathrm{mg} / \mathrm{kg})$ used in this study has been shown to produce diabetes of modest severity. Rats injected with streptozotocin at this dosage present with diabetes that is stable without insulin therapy $[27,28]$. The progression of the disease reported here, increase in 
Table 3. Volume fractions $(\%)$ and volumes $\left(\mathrm{mm}^{3}\right)$ of components of the inter-myocyte space of the left ventricle of control $(n=8)$, and diabetic $(n=8)$ Wistar rat hearts

\begin{tabular}{llll}
\hline & $\begin{array}{l}\text { Collagen } \\
\text { fibrils }\end{array}$ & $\begin{array}{l}\text { Amorphous } \\
\text { ground } \\
\text { substance }\end{array}$ & $\begin{array}{l}\text { Other } \\
\text { components }\end{array}$ \\
\hline $\begin{array}{l}\text { Volume fraction }(\%) \\
\text { Control }\end{array}$ & $31.77 \pm 3.3$ & $64.25 \pm 3.8$ & $3.98 \pm 0.6$ \\
Diabetic & $17.01 \pm 3.8^{\mathrm{a}}$ & $80.56 \pm 4.3^{\mathrm{a}}$ & $2.43 \pm 0.6 \mathrm{NS}$ \\
Volume $\left(\mathrm{mm}^{3}\right)$ & $13.5 \pm 2.6$ & $25.5 \pm 2.7$ & $1.71 \pm 0.4$ \\
Control & $103.5 \pm 12.4^{\mathrm{b}}$ & $3.19 \pm 0.7 \mathrm{NS}$ \\
\hline
\end{tabular}

Values are means \pm SEM. Comparison between control and diabetic groups was made using the Student's $t$-test; NS, no significant difference; ${ }^{\mathrm{a}} p<0.01 ;{ }^{\mathrm{b}} p<0.001$

blood glucose, reduction in body weight, and greater heart-to-body weight ratio is in line with that reported previously by ourselves and others [10, 13, 29]. The decreases in time to peak tension, reduced relaxation time and altered sensitivity to calcium are also in line with previously published data $[5,6,30]$. The lowered sensitivity to adrenalin could reflect an adaptation to the higher levels of catecholamines which have been reported in diabetic animals [31].

The structural changes that we report here represent global estimates of the main components of the coronary vasculature of the left ventricle, namely the capillary bed and associated post-capillary venules. These were obtained using unbiased stereological techniques designed for anisotropic tissues and using random sampling procedures. Sampling encompassed the entire left ventricle, rather than being restricted to papillary muscles or to epi- or endomyocardial locations as in some previous studies [32]. As a consequence of using global parameters the mean diameter of capillaries presented here, which includes post-capillary venules, is somewhat larger than previous reports of capillary diameter deduced from frequency distributions of transverse sections. It needs to be kept in mind that our figures are for the sheet of vascular luminal membrane including capillaries and venules, that is available for effective diffusion of oxygen and metabolites to the adjacent sarcolemma of the left ventricular myocytes. We consider this global figure to be of greater physiological importance than that of the capillary bed alone.
Table 5. Estimates of tissue thickness from capillary luminal membrane to sarcolemma and from myocyte mitochondrial outer membranes to capillary luminal membranes and their uniformity index for control $(n=8)$, and diabetic $(n=8)$ Wistar rat hearts

\begin{tabular}{llll}
\hline & $\begin{array}{l}\text { Arithmetic } \\
\text { mean tissue } \\
\text { thickness } \\
(\mu \mathrm{m})\end{array}$ & $\begin{array}{l}\text { Harmonic mean } \\
\text { tissue thickness } \\
(\mu \mathrm{m})\end{array}$ & $\begin{array}{l}\text { Uniformity } \\
\text { index } \\
\left(\mathrm{T}_{\mathrm{a}} / \mathrm{T}_{\mathrm{h}}\right)\end{array}$ \\
\hline Capillary luminal membrane to sarcolemma & \\
Control & $0.47 \pm 0.03$ & $0.31 \pm 0.03$ & $1.56 \pm 0.05$ \\
Diabetic & $0.72 \pm 0.04^{\mathrm{c}}$ & $0.46 \pm 0.03^{\mathrm{b}}$ & $1.57 \pm 0.07 \mathrm{NS}$ \\
Mitochondrial outer membrane to capillary luminal membrane & lumb \\
Control & $2.18 \pm 0.17$ & $1.47 \pm 0.06$ & $1.60 \pm 0.04$ \\
Diabetic & $2.35 \pm 0.09 \mathrm{NS}$ & $1.75 \pm 0.07^{\mathrm{a}}$ & $1.39 \pm 0.03^{\mathrm{c}}$ \\
\hline
\end{tabular}

Values are means \pm SEM. Comparison between control and diabetic groups was made using the Student's $t$-test; NS, no significant difference; ${ }^{\mathrm{a}} p<0.01 ;{ }^{\mathrm{b}} p<0.005 ;{ }^{\mathrm{c}} p<0.001$

We have demonstrated various morphological changes in the left ventricular myocardium of rats 48 days after the induction of diabetes. This may help to explain the pathophysiological changes associated with the onset of diabetes, i.e., increases in the volume of the intermyocyte space, accompanied by a decrease in the surface area of capillaries and venules of the myocardium, and extended diffusion distances from vascular lumen to mitochondria. These both confirm and extend the findings from other groups. The enlarged intermyocyte space, as we have demonstrated, agrees with the report of Thompson [11], who described an increase in interstitial tissue in rats 6 weeks after the onset of alloxan-induced diabetes, but failed to quantify the extent of the change. The greater volume of the extracellular space between myocytes is due to an apparently higher proportion of the amorphous components of the ground substance. This may represent a proliferation of some components of the extracellular matrix, or may be simply oedema.

The reduction in vascular surface area in the left ventricle is probably a result of a reduction in length and diameter of the capillaries and post-capillary venules, although neither of these alone was statistically significant. It should be remembered, however, that small reductions in capillary diameter may have profound implications on blood flow since the rate of flow in a tube such as a capillary is directly proportional to the fourth power of its radius. The change in

Table 4. Characteristics of left ventricular capillaries of control $(n=8)$, and diabetic $(n=8)$ Wistar rat hearts

\begin{tabular}{|c|c|c|c|c|c|c|}
\hline & $\begin{array}{l}\text { Length density } \\
\left(\mathrm{mm} / \mathrm{mm}^{3}\right)\end{array}$ & $\begin{array}{l}\text { Total length in } L V \\
(\mathrm{~mm})\end{array}$ & $\begin{array}{l}\text { Surface density } \\
\left(\mathrm{mm}^{2} / \mathrm{mm}^{3}\right)\end{array}$ & $\begin{array}{l}\text { Surface area } \\
\left(\mathrm{mm}^{2}\right)\end{array}$ & $\begin{array}{l}\text { Diameter (global) } \\
(\mu \mathrm{m})\end{array}$ & $\begin{array}{l}\text { Diameter } \\
(<8 \mu \mathrm{m})\end{array}$ \\
\hline Control & $4504 \pm 274$ & $2926337 \pm 203607$ & $77.49 \pm 3$ & $50313 \pm 2565$ & $7.01 \pm 0.22$ & $4.58 \pm 0.13$ \\
\hline Diabetic & $3948 \pm 368$ NS & $2634776 \pm 236172 \mathrm{NS}$ & $56.72 \pm 4^{\mathrm{a}}$ & $38202 \pm 3083^{a}$ & $6.51 \pm 0.33 \mathrm{NS}$ & $3.71 \pm 0.9^{\mathrm{a}}$ \\
\hline
\end{tabular}

Values are means \pm SEM. Comparison between control and diabetic groups was made using the Student's $t$-test; NS, no significant difference; ${ }^{\mathrm{a}} p<0.001$ 
Table 6. Volume fraction (\%) of left ventricular myocytes occupied by various organelles for control $(n=8)$, and diabetic $(n=8)$ Wistar rat hearts

\begin{tabular}{lllllll}
\hline & Cytoplasm & Lipid droplets & Lipofuscin & T-system & Mitochondria & Myofibrillae \\
\hline Control & $4.06 \pm 0.28$ & $0.78 \pm 0.11$ & $0.40 \pm 0.09$ & $2.55 \pm 0.17$ & $35.14 \pm 0.45$ & $57.07 \pm 0.52$ \\
Diabetic & $9.00 \pm 1.08^{\mathrm{a}}$ & $1.70 \pm 0.24^{\mathrm{a}}$ & $0.62 \pm 0.18 \mathrm{NS}$ & $3.83 \pm 0.31^{\mathrm{a}}$ & $25.19 \pm 1.00^{\mathrm{a}}$ & $59.66 \pm 0.90 \mathrm{NS}$ \\
\hline
\end{tabular}

Values are means \pm SEM. Comparison between control and diabetic groups was made using the Student's $t$-test; NS, no significant difference; ${ }^{\mathrm{a}} p<0.001$

mean tissue thickness between capillary lumen and myocyte sarcolemma is a reflection of the increased volume of intermyocyte space. The arithmetic and harmonic mean of tissue thickness between the capillary lumen (oxygen source) and the mitochondrial outer membrane (oxygen sink) is a direct indication of oxygen diffusion distance. This would seem to be a more meaningful parameter than the usually quoted maximal oxygen diffusion distance, which is based on intercapillary spacing derived from the Kroughs cylinder model [33]. The latter model does not take into account the heterogeneous distribution of mitochondria within myocytes [34]. Maximum diffusion distance for rat papillary muscle has been quoted as approximately $7 \mu \mathrm{m}$ [35]. It is therefore apparent from our values of the arithmetic mean of barrier thickness from mitochondrial outer membrane to capillary lumen of $2.18 \mu \mathrm{m}$ that mitochondria are most common in subsarcolemmal positions. This principle is well-established in fast oxidative glycolytic skeletal muscle fibres [34]. There was a significant increase in the harmonic mean of barrier thickness from mitochondria to capillary lumen but proportionately less than from lumen to sarcolemma. The diffusion distance for oxygen and metabolites will be least where a capillary surface is in close apposition to a myocyte and greater where it faces away from a myocyte. It is therefore apparent that the areas of close apposition of capillaries to myocytes are of most importance to diffusion. Therefore, the harmonic mean of tissue thicknesses, based on the reciprocals of the local thicknesses will be most informative, as diffusion is inversely proportional to the local tissue thickness.

There was no change in uniformity index of the latter indicating that the barrier was thickened in a regular fashion. The uniformity index of harmonic mean tissue thickness from mitochondria to capillary lumen fell, indicating a more regular barrier. This would suggest a loss of sub-sarcolemmal mitochondria or a rearrangement in favour of a more uniform distribution throughout the myocytes. This could be accommodated by a loss of some mitochondria, or a reduction in their individual size, either of which would be supported by the reduction in mitochondrial volume fraction described in this study.

To our knowledge the studies of Mall et al. [32,36], are the only other reports in which modern stereological methods have been used to objectively determine detailed changes in cardiac structure after the onset of diabetes. Comparison of the results reported here with those of Mall et al. [32, 36], show both similarities and differences. The length density of capillaries in our control animals is in the same range as that reported by Mall et al. [32], but somewhat higher and nearer the value that they report for their second batch of animals, the end-weight-matched controls. However, the studies of Mall et al. were restricted to the left ventricular papillary muscles and the duration of diabetes was only 28 days. These authors also used much younger animals in which body weight was maintained during the period in which they were diabetic. In the present study we used older animals in which the rate of growth has begun to slow down. These animals lose weight during the period of diabetes. To avoid the added complication of growth in the control animals we used onset controls as did Mall et al. [32]. Thus, the results reported here represent pathological changes from the initial non-diabetic state. It is highly unlikely that the changes reported are simply age-related. Rats of this age are in the stable region of their growth cycle. It is therefore most improbable that these apparently disadvantageous structural alterations would present as a result of 48 days of normal growth. The functional studies show that these changes take place in a tissue in which the contractility is decreased.

The structural changes that we demonstrate might well underlie the reduced function of the diabetic heart. The increase in the volume of extracellular components could increase the stiffness of the ventricular wall. The concomitant reduction in contractility would then result in a reduction in left ventricular ejection volume. The increased diffusion distance from capillary lumen to mitochondrial membranes demonstrated in the diabetic myocardium could lead to a reduced oxygen supply to the underlying myocytes; this would again be expected to lead to a reduction in function. In this latter respect our results are similar to several studies on the development of neuropathy after the onset of diabetes [37-39]. Studies on diabetic humans have shown a reduction in capillary density with no change in luminal perimeter and an increase in total diffusion distances in endoneural tissue from patients with severe neuropathy [37]. These authors showed that there was a direct correlation between capillary abnormalities and the severity of neuropathy. It has been proposed that reduced 
nerve blood flow underlies the development of neuropathy in streptozotocin-diabetic rats [38]. These suggestions are supported by the finding that central hypoxaemia in rats causes neurological defects similar to those which occur in experimental diabetes [39]. The results reported here suggest reduced oxygen delivery to the cardiac myocytes which themselves have a reduced content of mitochondria. Previous reports suggesting a loss of myofibrillae are not confirmed $[10,11]$. The increase in free cytoplasmic components observed in this study is attributable to a loss of mitochondria. The proliferation of lipid droplets and elements of the T-system may reflect a change in lipid metabolism. Further studies will determine whether reduced blood flow underlies the development of diabetic cardiomyopathy.

Acknowledgements. A. W. was supported by the Garfield Weston Foundation. The authors would like to thank Mr. E. W. Neville and Dr. J.P.T. Ward for carrying out the functional studies on the papillary muscles.

\section{References}

1. Ledet T (1976) Diabetic cardiopathy quantitative histological studies of the hearts from young juvenile diabetics. Acta Path Microbiol Scand 84: 421-428

2. Fien FS, Sonnenblick EH (1985) Diabetic cardiomyopathy. Progress in cardiovascular diseases. 27: 255-270

3. Rodrigues B, McNeill JH (1992) The diabetic heart: metabolic causes for the development of a cardiomyopathy. Cardiovas Res 26: 913-922

4. Hearse DJ, Stewart DA, Green DG (1978) Myocardial susceptibility to ischaemic damage: a comparative study of disease models in the rat. Eu J Cardiol 7: 437-450

5. Bouchard RA, Bose D (1991) Influence of experimental diabetes on sarcoplasmic reticulum function in rat ventricular muscle. Am J Physiol 260: H341-H354

6. Cameron NE, Cotter MA, Robertson S (1989) Contractile properties of cardiac papillary muscle in streptozotocin diabetic rats and the effects of aldose reductase inhibition. Diabetologia 32: 365-370

7. Nobe S, Aomine M, Arita M et al. (1990) Chronic diabetes prolongs action potential duration of rat ventricular muscles: circumstantial evidence for impaired $\mathrm{Ca}$ channel. Cardiovas Res 24: 381-389

8. Lagadic-Gossman D, Feuvray D (1990) Decreased sensitivity of contraction to changes of intracellular $\mathrm{pH}$ in papillary muscle from diabetic rat hearts. J Physiol 422: 481497

9. Factor SM, Bhan R, Minase T et al. (1981) Hypertensivediabetic cardiomyopathy in the rat an experimental model of human disease. Am J Pathol 102: 219-228

10. Jackson CV, McGrath GM, Tahliani AG et al. (1985) A functional and ultrastructural analysis of experimental diabetic rat myocardium manifestation of a cardiomyopathy. Diabetes 34: 876-883

11. Thompson EW (1988) Structural manifestations of diabetic cardiomyopathy in the rat and its reversal by insulin treatment. Am J Anat 182: 270-282

12. McGrath GM, McNeill JH (1986) Cardiac ultrastructural changes in streptozotocin-induced diabetic rats: effects of insulin treatment. Can J Cardiol 2: 164-169
13. Seager MJ, Singal PK, Orchard R et al. (1984) Cardiac cell damage: a primary myocardial disease in streptozotocin-induced chronic diabetes. B J Exp Pathol 65: 613-623

14. Fischer VW, Leskiw ML, Barner HB (1981) Myocardial structure and capillary basal laminar thickness in experimentally diabetic rats. Exp Mol Pathol 35: 244-256

15. Ledet T, Neubauer B, Christiensen NJ, Lundbaeck K (1979) Diabetic cardiopathy. Diabetologia 16: 207-209

16. Sunni S, Bishop SP, Kent SP, Geer JC (1986) Diabetic cardiomyopathy. Arch Pathol Lab Med 110: 375-381

17. Hayat MA (1981) Fixation for electron microscopy. Academic Press London

18. Warley A, Daniel PM, Guthrie DL (1987) Diabetes mellitis in the rat: diminution in the number of cells in the thymus and of lymphocytes in the blood. Q J Exp Physiol 72: 609615

19. Weibel ER (1979) Stereological methods. (Practical methods for biological morphometry, vol 1) Academic Press, London

20. Mattfeldt T, Mall G, Gharehbaghi H, Moller P (1990) Estimation of surface area and length with the orientator. J Microsc 159: 301-317

21. Gundersen HJG (1977) Notes on the estimation of the numerical density of arbitrary particles: the edge effect. J Microsc 111: 219-223

22. Mayhew TM, Momoh CK (1974) Stereological description of the anterior horn cervical cord of the adult rat. A quantitative study using the optical microscope. J Comp Neurol 156: $107-122$

23. Hyde DM, Buss DD (1986) Morphometry of the coronary microvasculature of the canine left ventricle. Am J Anat 177: $415-425$

24. Jensen EB, Gundersen HJG, Osterby R (1979) Determination of membrane thickness distribution from orthogonal intercepts. J Microsc 115: 19-33

25. Jackson MR, Joy CF, Mayhew TM, Haas JD (1985) Stereological studies on the true thickness of the villous membrane in human term placentae: a study of placentae from high-altitude pregnancies. Placenta 6: 249-258

26. Ward JPT (1990) Cardiac muscle function following chronic dietary potassium depletion in the rabbit. Cardiovas Res 24: $647-652$

27. Junod A, Lambert AE, Orci L, Pictet R, Gonet AE, Renold AE (1967) Studies on the diabetogenic action of streptozotocin. Proc Soc Exp Biol Med 126: 201-205

28. Junod A, Lambert AE, Staffacher W, Renold AE (1969) Diabetogenic action of streptozotocin: relationship of dose to metabolic response. J Clin Invest 48: 2129-2139

29. Warley A (1991) Changes in sodium concentration in cardiac myocytes from diabetic rats. Scanning Microsc 5: 239245

30. Fein FS, Kornstein LB, Strobeck JE, et al. (1980) Altered myocardial mechanics in diabetic rats. Circ Res 47: $922-$ 933

31. Gøtzsche O (1985) Abnormal myocardial calcium uptake in streptozotocin diabetic rats. Evidence for a direct insulin effect on the catecholamine sensitivity. Diabetes 34 : 287-290

32. Mall G, Baust H, Hasslacher Ch et al. (1987) Synergistic effects of diabetes mellitus and renovascular hypertension on the rat heart - stereological investigations on papillary muscles. Virchows Arch 411: 531-542

33. Hudlica O, Eggington S, Brown MD (1988) Capillary diffusion distances - their importance for cardiac and skeletal muscle performance. NIPS 3: 134-138

34. Weibel E (1984) The pathway for oxygen. Harvard University Press, Cambridge 
35. Loud AV, Beghi C, Olivetti G, Anversa P (1984) Morphometry of right and left ventricular myocardium after strenuous exercise in preconditioned rats. Lab Invest 51: 104111

36. Mall G, Mann J, Hasslacher C et al. (1991) Morphometric study on the rat heart in combined renovascular hypotension and diabetes mellitus: evidence of early synergistic effects on myocytes. In: Nagato M, Dhalla NS (eds) The diabetic heart. Raven Press, New York pp 115-124

37. Malik RA, Newrick PG, Sharma AK et al. (1989) Microangiopathy in human diabetic neuropathy; relationship be- tween capillary abnormalities and the severity of neuropathy. Diabetologia 32: 92-102

38. Cameron NE, Cotter MA, Low PA (1991) Nerve blood flow in early experimental diabetes in rats: relation to conduction deficits. Am J Physiol 261: E1-E8

39. Smith WJ, Diemel LT, Leach RM, Tomlinson DR (1991) Central hypoxemia in rats provokes neurological defects similar to those seen in experimental diabetes mellitus: evidence for a partial role of endoneural hypoxia in diabetic neuropathy. Neuroscience 45: 255-259 